\title{
Gamification in education: Serious Game Prototype for Children with Special Needs
}

\author{
Eman Hassan Shaltout \\ Information Technology Dept \\ Faculty of Computers and Information \\ Menoufia University, Egypt \\ eman.shaltoot@ci.menofia.edu.eg
}

\author{
Ahmed Afifi \\ College of Computer Science and \\ Information Technology, King Faisal \\ University, KSA \\ Information Technology Dept \\ Faculty of Computers and information \\ Menoufia University, Egypt \\ aafifi@kfu.edu.sa
}

\author{
Khalid M. Amin \\ Information Technology Dept \\ Faculty of Computers and Information \\ Menoufia University, Egypt \\ k.amin@ci.menofia.edu.eg
}

\begin{abstract}
Gamification or integrating game elements within the non-game environment is widely used to improve systems, services, and the overall user experience. It is mainly intended for education purposes, not for mere entertainment. Gamification can provide many benefits like creating a stimulating environment for learning and engagement with content in an unconventional way. These benefits are vital for the education of children with special needs because they suffer from constant distraction and loss of motivation. Therefore, we introduce a serious game prototype for children with special needs. The main purpose of this serious game is to assess total reading and understanding the impact of augmented reality as a learning methodology. This game is a complementary approach to motivate students after using an AR learning environment. This assessment game was designed according to the systemic gamification principles and contains the elements of game formula like points, time, and player profile. It will be used to assess children after learning sessions using $A R$ and flashcards. The card assessment game is an unconventional way to evaluate children. Each child is different from her/his peers in the academic level, so the number of words is chosen at the beginning of the game based on what the child has learned in the training sessions. The child profile result confirmed that the game can be used in assessment. Moreover, parents and specialists confirmed that children enjoyed the assessment session, and the game is not limited to test only, as some children play it for language development.
\end{abstract}

Keywords-Gamification, Mobile Based game, Serious games, children with special needs, Education, Augmented Reality.

\section{INTRODUCTION}

Children with special needs always need continuous development in learning methods and assessment approaches $[1,2,3]$ Specialists are constantly aiming to motivate them to engage in new and innovative learning methods by using gamification and serious games to maximize their access to quality learning. Therefore, utilizing gamification in learning and assessment became one of the most prevalent methods that supports children's motivation and encourages them to learn and enjoy the learning sessions [1].

As shown in [4], gamification can be used for many purposes other than mere entertainment. Serious games are based on achieving their purpose such as learning, but entertainment and fun are used only to achieve the desired goal of the game. Authors stressed that one of the most attractive factors is the type of game components. It is important to make the game successful and determine the mechanics and dynamics of the game. Authors arranged the game elements as follows: The components, which can be represented as points, levels, and avatars, in turn lead to achieving the mechanics of the game, which is represented in the reward system and encouragements. Then we can reach the dynamic, which is represented in the player's sense of progress in the game and close to winning.

Smart mobile devices gave serious games a huge leap forward, given its mobility, flexibility, and ability to use in any time needed [5,6]. Mobile is an incentive for education and one of the means that makes games easy to use. Games for children with special needs, among other methodologies, motivate and enhance their learning curve. They also ensure a way to monitor the children's level in an interesting and entertaining manner during their learning sessions [2,5]. Authors in [3] showed that games can be also used in learning assessment. Special game components can be developed for assessment and evaluation. Moreover, it can be incorporated as method to follow a student's advancement and progress.

This work is an automatic assessment method for the AR environment proposed in [7]. We introduce a Serious Game (SG) for evaluating children learning outcome after an Augmented Reality training session. The training period itself was 15 sessions per week for each child. At the beginning there would be a profile filled for each child to analyze her/his Quiz results. After completing the quiz, there are rewards given to the child, and points that collected for each correct answer to a question.

This article is organized as follows: Section 2 presents the Related work. Serious game design and implementation is discussed in Section 3. Section 4 shows the SG Experimental Setup. The results and evaluation are analyzed in Section 5 and finally conclusion and future work are discussed in Section 6.

\section{RELATED WORK}

There is numerous research that tackle serious games for education. However, authors mostly address healthy children

Proceedings of $1^{\text {st }}$ International Conference on Computers and Information, ICCI 2021 
not children with special needs. Even games developed specially for children with special needs mostly address the problem of facial expressions and emojis. In [8], 40 serious games were analyzed. Most of these games encompasses the problem of facial expressions as we previously mentioned.

Authors in [6], introduced a quiz game for primary school children called "Quizbot". It is a board game intended to make the child more focused during the test without relying on traditional methods. The game is played with a robot across the board. The student moves that robot in different directions to get the question. The child then moves it again to choose the correct answer. Some obstacles are faced to make the test more fun and motivating students. All previous elements were designed through tablet as tactile version. The quiz is designed in another methodology as a tangible version. It depends on the implementation of the "Quizbot" with all its elements, but more realistic, the board in which the student moves to connect to the questions and answers is placed on the floor. Board, bombs, walls, and robots are physical artifacts that participants can do physically. The Results proved that children enjoy using the tablet digital version instead of the tangible version. The questions are constructed as multiple-choice, matching, and true and false.

Several researchers revolve around teaching children's different skills through augmented reality technology because of its motivating approach in children's learning. Augmented reality is about merging reality with an imaginary environment, which provides a fun aspect to sessions. Children are assessed through interesting games to increase the children's motivation and maximize their gain from the benefits of technology $[9,10$, $11]$.

Augmented reality was utilized in [10] to develop a Gamebook. Each chapter of the book contains an emotion. A description is provided through a story that explains this emotion with a voice narration of the story. The child then links the story with the three-dimensional emotion. After each chapter, there is a Quiz. The child chooses the emotion that describes the story included in the book. At the end of all chapters, there is another quiz based on linking two similar emotions.

Another approach proposed in [11] teaches pre-school children how to use augmented reality to learn about animals and Bangla alphabets. After each learning session, there is a quiz session to assess how much children can learn from the AR content. In the first quiz, children are given an alphabetical letter and three pictures. They are then asked to choose the picture whose name begins with that letter. The test is then reversed where they are asked to choose one letter from a list of three letters that corresponds to the picture.

The previous works show the extent of the authors' interest in using serious games, but most of them concentrate on normal children only. Also, most of the research directed to children with special needs is focus only on the problem of emotions learning because of its difficulty in understanding for those children.

\section{SERIOUS GAME DESIGN AND IMPLEMENTATION}

The traditional pedagogical learning methods like educational cards alone, and the repetition of words for the child to learn become very boring for children with special needs and can't attract children's attention. A new interesting learning methodology which utilizes augmented reality and educational cards was proposed in [7]. This method can teach children the totally readding, which depends on seeing the whole word and does not separate it to letters. The child learns to read the card based on the application of augmented reality, which was reading the card in front of the child and displaying a 3D virtual object related to this word. Through this process, she/he relates the card to its corresponding object and its pronunciation.

In [7], a traditional assessment methodology was used, and the learning outcome was evaluated by passing the card in the front of the child and asking her/him to read the card or make a choice from several cars. Considering the characteristics of children with special needs, this assessment methodology is not enough to attract the child's attention and make the evaluation sessions interesting, like the training sessions. Therefore, our aim here is to integrate a new and interesting methodology for children assessment. We seek to motivate the children during the assessment as well as the learning.

In this work, we will propose a serious game for child's assessment. It's applied after children with special needs completed their training sessions. In training sessions, we have been educated them the implicit groups and total reading method through an Augmented Reality (AR) technology. We have designed a SG prototype to assess children and determine their level and interact with utilizing AR technology in learning.

\section{A. The Desighn of the Serious Game Prototype}

The design and implementation of the card assessment game have been based on user experience and User-Centered Design UCD [5, 12, 13]. Using UCD would also improve the user experience across several phases of design and develop a seamless software with high usability, and satisfactory experience. During the design stage, we did not overlook the use of the Game frameworks to ensure serious game success and try to implement its features on our game [8]. We follow the following steps for game design:

\section{1) Data Collection}

We have collected major information on the behavior of children with special needs, in addition to the opinion of specialists on games that motivate children, as well as tips from parents. Specialists' advice on game architecture was also gathered. Data was collected on the condition of the children and the best way to build the game for them.

\section{2) Game Requirements and objectives}

The objective of the game was clarified, which is to use it to assess children. Some specialists also confirmed that it could be one of its objectives, not only the evaluation but also enjoying the sessions. It also plays a role in teaching the child words, starting to learn the concept of time and loss-winning feeling.

Proceedings of $1^{\text {st }}$ International Conference on Computers and Information, ICCI 2021 
The main goal of the game is to provide an unconventional assessment method which increases the child's motivation.

\section{3) Game Design Solution}

After the data was collected and the game objectives were determined, we started designing the storyboard, presenting it to the specialists and collecting their opinions. We combined these recommendations with Serious Game Frameworks to ensure the game successes [8].

One of the research [8] recommendations after analyzing 40 games was to use a framework before starting the game design to reach the best outcome and to ensure its success. This framework successfully applied for game when some of its attribute presented in the game. We used two of these frameworks and apply the suitable attributes in the proposed assessment game. The yusoff's framework, which has 12 attributes, and khowaja's framework, which has 20 attributes, are used to complete game design properly. Authors in [8] list attributes of frameworks which are among the determinants that the arbitrators of the games use to evaluate the game through and the extent to which they are applied to the game or not.

the framework scale depends on applying attributes in the game, when all attribute applied the result equals 2 , If the attributes are partially applied, the result equals 1 andif all attributes are not applied, the result equals 0 . When all attributes applied for game the Yusoff's scale attributes scores will be 24 and 40 for Khowaja's Scale.The attributes of frameworks which were applied in our card assessment game is listed in table I alonge their description. We applied 5 attributes from Yusoff's framework and 9 from Khowaja's framework. The score scale for our game is 10 for Yusoff's scale and 18 for Khowaja's Scale. We should enhancement this score by applying all attributes in the full game version [8].

So, our game design presents all attributes listed in table 1, In addition to the main components of the game, which are rewards, points, and a profile for each child [2]. Using UX, UCD, SG framework and Gamification component help in the success of the game and make it more impactful.

\section{4) Game Scenarios and Implementation}

To implement the game, Unity game engine, C\# language for programming and Photoshop to edit images was used. The game interface was developed by using Unity and Adobe Photoshop. As mentioned before, Game design depends on User-Centered-Design and User experience Methodology.

As previously mentioned, the game is a tool used to ensure that children learn through educational flashcards and AR Fig. 1 , shows an example of the application which used in training sessions. It shows one card from each implicit group with it' $3 \mathrm{~d}$ modal using augmented reality. The game consists of one level containing several sub-levels. Each sub-level contains more than one word that the child has learned in previous training sessions. Each child can understand several words different from her/his peers based on the child's condition. These words can range from 5-10-15-25.

The number of words is based on the opinion of specialists and pedagogical method from the beginning in the training sessions as illustrated in [7]. The main introductory game screen is shown in Fig. 2(a). The intro screen features the application part of training children using AR, as well as the Game itself. There is also a screen explaining the game and how to use it.

At the start of the game, there is a profile that the child or her/his supervisor fills, to record the results of each child Fig. $2(b)$.

TABLE I. SAMPLE OF YUSOFF'S AND KHOWAJA'S FRAMEWORK ATTRIBUTES

\begin{tabular}{|c|c|}
\hline Attribute & Description \\
\hline Incremental learning & $\begin{array}{l}\text { In the game, we implement incremental and } \\
\text { sequential learning until the child knowledge is } \\
\text { increased from } 5 \text { to } 25 \text { word }\end{array}$ \\
\hline Instruction method & $\begin{array}{l}\text { The method of the game is education through } \\
\text { effective interaction of the child }\end{array}$ \\
\hline Interaction & $\begin{array}{l}\text { Which represented in engagement children in } \\
\text { learning }\end{array}$ \\
\hline $\begin{array}{l}\text { Transfer of learned } \\
\text { skills }\end{array}$ & $\begin{array}{l}\text { use the traditional element and methodology as } \\
\text { guide for our game, with attractive means }\end{array}$ \\
\hline Instructional Strategies & $\begin{array}{l}\text { The game in our case here is based on motivation } \\
\text { and focuses on learning through assessment }\end{array}$ \\
\hline Game mechanics & $\begin{array}{l}\text { The rules of the game are set on how to win and } \\
\text { lose depend on the correct answer and feeling with } \\
\text { time }\end{array}$ \\
\hline Game dynamic & $\begin{array}{l}\text { represented in the player's sense of progress in the } \\
\text { game }\end{array}$ \\
\hline Game story & $\begin{array}{l}\text { A full story board game was pre-drawn to game } \\
\text { development. }\end{array}$ \\
\hline $\begin{array}{l}\text { Game-based learning } \\
\text { Attributes }\end{array}$ & $\begin{array}{l}\text { The game is a test that evaluates effective learning } \\
\text { of the children }\end{array}$ \\
\hline Scaffolding & We help children within game based on sound \\
\hline Narratives & $\begin{array}{l}\text { For each card there is sound, in addition to } \\
\text { encouraging voices when child choose correct } \\
\text { answer }\end{array}$ \\
\hline $\begin{array}{l}\text { Intended } \\
\text { outcomes }\end{array}$ & Evaluate the child's level in total reading \\
\hline Reward & $\begin{array}{l}\text { Represented by points, encouraging voices when } \\
\text { child win. }\end{array}$ \\
\hline User profile & $\begin{array}{l}\text { Each player has his own profile with his } \\
\text { information in the game among the player's in- } \\
\text { game motivators. We use it to analyze the child } \\
\text { result }\end{array}$ \\
\hline
\end{tabular}




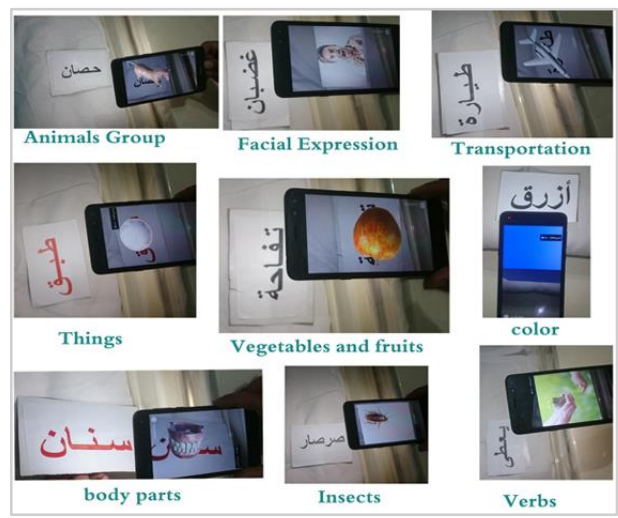

Fig. 1. sample cards from each implicit group

The game design is shown in Fig. 2(c). It consists of the card that the child learns and three pictures and The child drags correct one from three pictures and drops it onto the card. This eliminates any answer miss-placed, as happens by clicking on the correct answer. There is a sound icon that can be pressed to pronounce the name of the word on the card to help the child. As for winning, it is achieved through time and points that the child gained for answering each question with an audible voice that encourages the child on each correct answer.

Within the card game assessment each question is timed to 24 seconds. This time is estimated by educational specialists for child by calculating child thinking time, drag and drop time and playing the sound of the card.

\section{5) Design Evaluation}

The game was evaluated and its usability through experience with the children themselves, and the suggestions and difficulties they faced to improve it in the future were taken. This stage is one of the stages of ensuring the quality of the software's portability and its ability to be used easily by children and supervisors. Indeed, this stage sometimes was returned to a previous step.

\section{SERIOUS GAME EXPERIMENTAL SETUP}

SG was applied to 4 children with special needs. Children aged between 7-12 years old. One down Syndrome child and three autistic children. Autism severity is moderate for these children. Autistic children have good memory, unlike down syndrome children. Firstly, children were trained along 15 sessions, Using AR educational cards, following the methodology proposed in [7]. Secondly, after training there was a session to teach and train the children about the game elements and how to win. At the end, the game was applied as an unconventional assessment. The game was also tested with each child in a separate session. The flow chart shown in Fig.3 shows how a child plays a game of cards and completes all the questions.

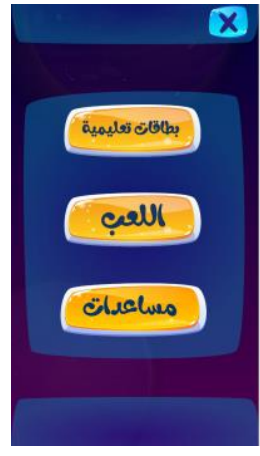

(a)Main Menu

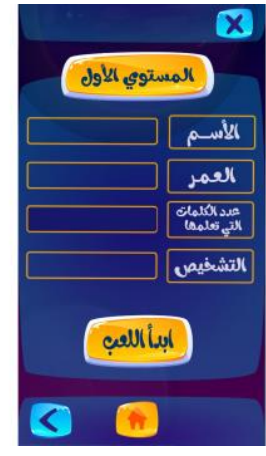

(b)Child Profile

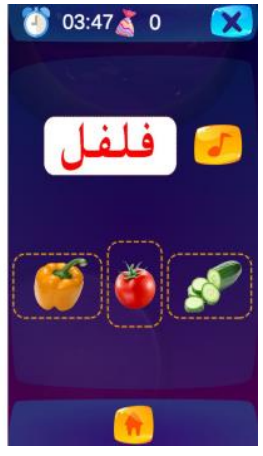

(c)Game Mechanism
Fig. 2. Serious Game Design Scenes

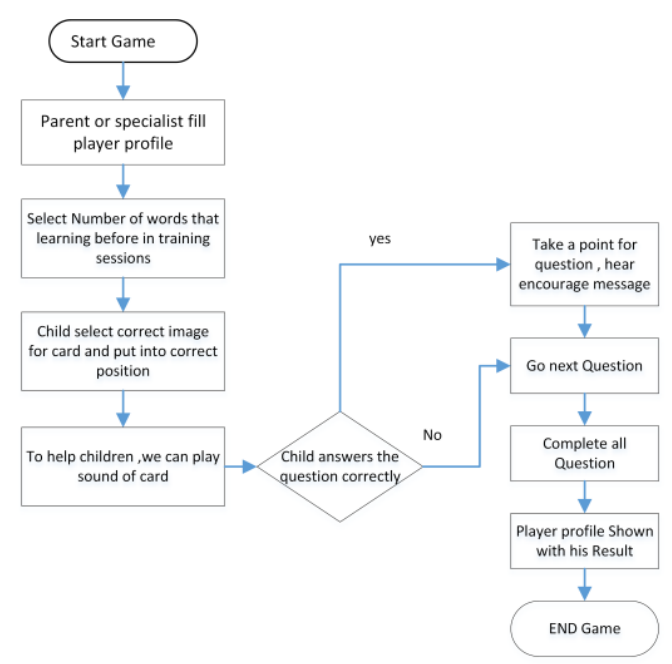

Fig. 3. SG Playing Steps

\section{RESUlt AND EVALUTION}

The evaluation of the game for children depends on the time factor in addition to the number of points scored by the child, which expresses the number of words that have been answered correctly. When the child has answered half of the words in addition to taking 24 seconds for each question or less, then he has won the game. We make sure that the child has learned through the augmented reality of the words and his ability to use the game as assessment.

Table II shows the result for each child based on the child's profile. Results show that AR is one of the productive methods in teaching children with special needs in short time, whereas the training sessions was through 15 sessions per week. Furthermore, the unconventional assessment was a fun activity for the child and using the game in the assessment made the children enjoy the sessions time. This was confirmed by parents based on the child's will to repeat the game more than once. The result indicates child still need a lot of training in keeping track of time, being one of the factors for winning. Also, the result indicates the time can be increased because of children 
TABLE II PLyERS RESUlT

\begin{tabular}{|l|l|l|l|l|l|l|l|}
\hline Player & Disability & $\begin{array}{l}\text { Total } \\
\text { time in } \\
\text { seconds }\end{array}$ & $\begin{array}{l}\text { One question } \\
\text { Duration/seconds }\end{array}$ & $\begin{array}{l}\text { Time taken in } \\
\text { playing game } \\
\text { in seconds }\end{array}$ & $\begin{array}{l}\text { Number } \\
\text { of words } \\
\text { learned }\end{array}$ & Point & Description \\
\hline Player 1 & Autism & $600 \mathrm{~s}$ & $7.6 \mathrm{~s}$ & $177 \mathrm{~s}$ & 25 & 23 & $\begin{array}{l}\text { Child answer all question without playing sound } \\
\text { unlike 2 wrong answers for emotion cards, despite } \\
\text { playing card sound }\end{array}$ \\
\hline Player 2 & Autism & $360 \mathrm{~s}$ & $15.6 \mathrm{~s}$ & $165 \mathrm{~s}$ & 15 & 10 & $\begin{array}{l}\text { Child has a problem in drag and drop the correct } \\
\text { answer, she can only answer 10 word, 6 without } \\
\text { playing sound and 4 with playing sound }\end{array}$ \\
\hline Player 3 & Autism & $360 \mathrm{~s}$ & $13.3 \mathrm{~s}$ & $174 \mathrm{~s}$ & 15 & 13 & $\begin{array}{l}\text { Child answer all word without playing sound. } \\
\text { There are 2 wrong answers because of Impulsive } \\
\text { behavior in answering }\end{array}$ \\
\hline Player 4 & $\begin{array}{l}\text { Down } \\
\text { Syndrome }\end{array}$ & $120 \mathrm{~s}$ & $15 \mathrm{~s}$ & $60 \mathrm{~s}$ & 5 & 4 & $\begin{array}{l}\text { Child answer 2 question correctly without any } \\
\text { help and another 2 after playing the sound of card. }\end{array}$ \\
\hline
\end{tabular}

disability of drag and drop word to the correct answer. Furthermore, Parent or specialist can help children in drag and drop the correct word after child already select it. Children with a high educational level, still couldn't recognize emotion and have a problem with it. User experience Questionnaire was used to gather the opinion of specialists and parents.

The short version of the questionnaire was used. It enables to form an overview of the user experience as a whole without delving into detailed feedback. This is the initial significant aspect to determine if the games achieve the goal in evaluating children. For Specialist, we gather their opinions about the game.

Based on research $[5,13]$ the questions are laid out as follows Fig. 4, while the result is quantified on a rate of answer depending on 7-point Likert scale [14].

The questionnaire was filled out by 4 parents and 2 specialists. The mean scale for each question was calculated as shown in Fig. 5 and the answer was rated from -3 to +3 . The question which represents as negative question, its answer will be with negative for instance "The element of game confusing for a child" the mean scale was - 1 which represent the game is easy for children. The results of the questionnaire show the degree to which parents are adequately satisfied with the game. It is one of the useful and unconventional methods of evaluating children. Moreover, some specialists mentioned that some children may learn from the game and not only achieve the goal of evaluation. Specialists' opinions see the children need a continuous motivation and gamification achieve these targets. There is another opinion that expresses the need to change the sound played in error messages which is "answer not correct", because it is not understood by children. Yet generally, the game delivered results and made the children enjoy their time during the session. The supervisors see the drag and drop make the game difficult for child, which represented by Q2 in the questionnaire and its scale is 0.33 . the highest answer was for "game is mediocre for a child and has no interesting element" which make us sure the children like this game and attract them.

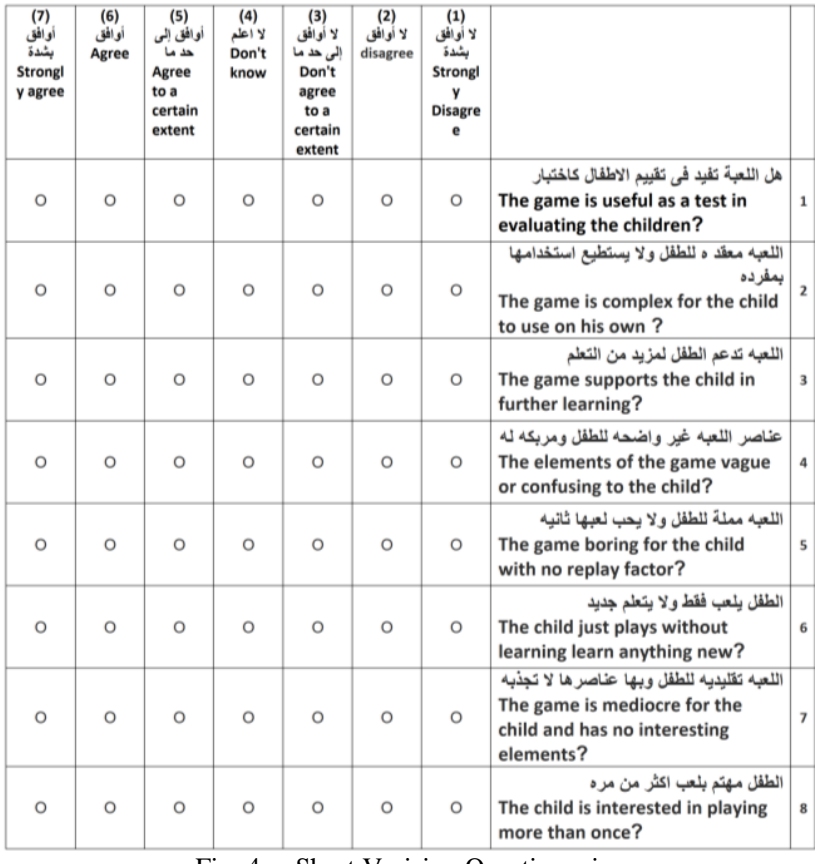

Fig. 4. Short Verision Questionnaire

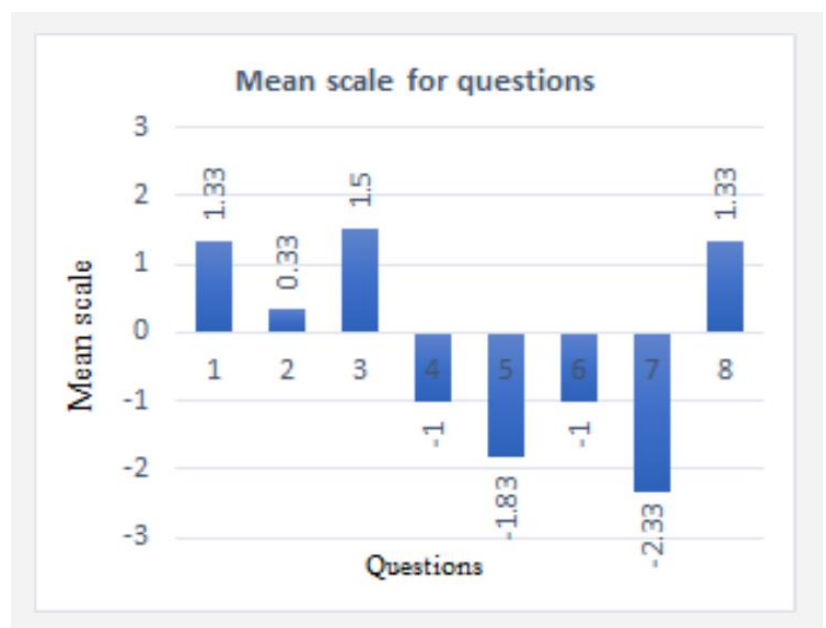

Fig. 5. Mean Scale for each question in Questionnaire 


\section{CONCLUSION AND FUTURE WORK}

People with special needs are essential individuals in societies and cannot be neglected from society. They have rights just like all of us.

Serious Game and gamification are valuable means in modern learning environments and considered as innovative methods to create an enjoyable learning environment for children. The time has come for special needs people to enjoy their learning sessions through serious games, as a learning method not merely intended for entertainment.

Serious games are used in evaluating children as a nontraditional way of testing. Therefore, we created a game to evaluate children after being previously trained on educational cards using AR technology. This game is a first prototype to evaluate children and to determine the potential opportunities of using games with them. The Results showed the children's level of enjoyment out of the game, as well as gathering the opinion of specialists and parents. Both confirmed that altering the assessment method to be in the form of a game proved to be a productive approach with children, and that AR technology had an effective role in training children and learning total reading

This makes us aspire to use serious games in the future on a larger sample of children with special needs. Also, we will add more advanced levels of difficulty. In addition, we can integrate the augmented reality technology into the games to achieve the best results and enjoyment in the sessions. Specialist feedback and the children's enthusiasm for using technology and playing games encourage us to use such games on more complex topics for children like emotions. We will also work to increase the game advantages by measuring the child's focus time in sessions depending on face detection and recognition. This will measure and analyze results accurately and help specialists to optimally evaluate the use of games with children in their education.

\section{REFERENCES}

[1] R.Smiderle, S.J.Rigo, L.B.Marques,J.A. Coelho and P.A.Jaques "The impact of gamification on students'learning, engagement and behavior based on their personality traits" Smart Learn. Environ, https://doi.org/10.1186/s40561-019-0098-x, 2020.

[2] K.D.Amina and B.Fatima" MEDIUS: A Serious Game for Autistic Children Based on Decision System" Simulation \& Gaming.49(4):423-440. doi:10.1177/1046878118773891, 2018.

[3] R.N. Landers, M.B. Armstrong, and A.B. Collmus, "How to Use Game Elements to Enhance Learning: Applications of the Theory of Gamified Learning" pp 457-484, Springer International Publishing, Serious Games and Edutainment Applications, DOI 10.1007/978-3-319-51645-5_21,2017.

[4] C. Dichev and D.Dicheva "Gamifying education: what is known, is believed and what remains uncertain: acritical review" Int J Educ Technol High Educ 14.https://doi.org/10.1186/s41239-017-0042-5, 9 (2017).

[5] C.MEFTAH, A.RETBI, S.BENNANI and M.K.Idrissi" Evaluation of User Experience in the context of Mobile Serious Game" 2019 International Conference on Intelligent Systems and Advanced Computing Sciences (ISACS), pp. 1-5, doi: 10.1109/ISACS48493.2019.9068872, 2019.

[6] F.G.Sanjuan, S.Jurdi, J.Jaenand V.Nacher," Evaluating a tactile and a tangible multi-tablet gamified quiz system for collaborative learning in primary education" , Computers \&Education ,doi: 10.1016/j.compedu.2018.04.011,2018.

[7] E. H. Shaltout, A. Afifi and K. M. Amin, "Augmented Reality Based Learning Environment for Children with Special Needs," 2020 15th
International Conference on Computer Engineering and Systems (ICCES), doi: 10.1109/ICCES51560.2020.9334571,2020.

[8] A.Hassan ,N.Pinkwart and M.Shafi," Serious games to improve social and emotional intelligence in children with autism" Entertainment Computing,pp 65-84, doi.org/10.1016/j.entcom.2021.100417,Vol 38,2021.

[9] C. Lin,H , Chai, J. Wang, C Chen, Y. Liu and Y. Huang, Augmented reality in educational activities for children with disabilities. Displays, 42, 51-54.doi:10.1016/j.displa.2015.02.004,2016.

[10] V. Carvalho, Jorge Brandão, Pedro Cunha, José Vasconcelos and F. Soares "Tobias in the Zoo - A Serious Game for Children with Autism Spectrum Disorders." Int. J. Adv. Corp. Learn, Psychology, Computer Science, DOI:10.3991/IJAC.V8I3.4897, 8 (2015).

[11] Abrar M.F., Islam M.R., Hossain M.S., Islam M.M., Kabir M.A. (2019) Augmented Reality in Education: A Study on Preschool Children, Parents, and Teachers in Bangladesh. In: Chen J., Fragomeni G. (eds) Virtual, Augmented and Mixed Reality. Applications and Case Studies. HCII 2019. Lecture Notes in Computer Science, vol 11575. Springer, Cham. https://doi.org/10.1007/978-3-030-21565-1_14,2019.

[12] M. Aguilar , C. Zapata, "Integrating UCD and an Agile Methodology in the Development of a Mobile Catalog of Plants" Springer International

Publishing Switzerland ,Advances in Ergonomics Modeling, Usability \& Special Populations, Advances in Intelligent Systems and Computing 486, DOI 10.1007/978-3-319-41685-4_8,75-87,2017.

[13] Carrión M. et al. (2020) Designing a Serious Game for Labor Inclusion of People with Intellectual Disabilities Using iPlus Methodology. In: Ahram T., Falcão C. (eds) Advances in Usability, User Experience, Wearable and Assistive Technology. AHFE 2020. Advances in Intelligent Systems and Computing, vol 1217. Springer, Cham. https://doi.org/10.1007/978-3-03051828-8_79

[14] M. Schrepp , A. Hinderks and J. Thomaschewski , " Design and Evaluation of a Short Version of the User Experience Questionnaire (UEQS) ". International Journal of Interactive Multimedia and Artificial Intelligence, Vol. 4, Nº,2017.

[15] Jamieson, Susan. "Likert scale". Encyclopedia Britannica, Invalid Date, https://www.britannica.com/topic/Likert-Scale. Accessed 23 July 2021.

Proceedings of $1^{\text {st }}$ International Conference on Computers and Information, ICCI 2021 